La visita pastoral como fuente privilegiada para la historia local: un ejemplo de la Nueva España en los siglos XVII y XVIII

Ana de Zaballa Beascoechea

Universidad del País Vasco UPV/EHU (España) 



\title{
La visita pastoral como fuente privilegiada para la historia local: un ejemplo de la Nueva España en los siglos XVII y XVIII
}

\section{The pastoral visit as a privileged source for local history: an example of the New Spain in the 17th and 18th centuries}

\author{
Ana de Zaballa Beascoechea \\ Universidad del País Vasco UPV/EHU (España) \\ ana.dezaballa@ehu.eus
}

Fecha de recepción: 21 de diciembre de 2020

Fecha de aceptación: 10 de abril de 2021

\section{Resumen}

En este artículo se plantea la riqueza de la visita pastoral del obispo a su diócesis como fuente para conocer la vida y la sociedad, tanto de localidades concretas como de regiones. La visita pastoral era desde el concilio de Trento, una obligación anual del obispo. En Indias la realidad es que pocos prelados lograron hacer la visita completa a su territorio debido a la amplitud territorial de estos obispados, pero contamos con unas cuantas visitas en el ámbito de la Nueva España que permiten conocer aspectos a nivel local, tanto de su organización social como territorial, su actividad agropecuaria o artesanal; siempre dependiendo de los intereses del obispo y por tanto del contenido del Diario de visita. Esta documentación puede contrastarse con otras fuentes eclesiásticas que la completen como los libros de cordilleras, o los procesos de los tribunales eclesiásticos.

Palabras clave: Historia local; Visita pastoral; Diario de Visita; Nueva España; Siglos XVII-XVIII.

\section{Abstract}

In this article, the richness of the bishop's pastoral visit to his diocese is presented as a source of knowledge about the life and society of both specific towns and whole regions. Since the Council of Trent, the pastoral visit has been an annual 
La visita pastoral como fuente privilegiada... - A. de Zaballa Beascoechea

obligation of every bishop. In the Indies, very few prelates were able to make a complete visit to their territories due to the large expanse of these bishoprics, but information on several visits in the New Spain area are available, so that they allow us to know local elements of their social, or territorial organization, as well as their agricultural or industrial activity, always depending on the interests of the bishop as reflected in the content of each visit diary. This documentation can be contrasted with other ecclesiastical sources that complete it such as "Cordilleras's" books, or the processes of the ecclesiastical courts.

Keywords: Pastoral visit; Visitor's Diary; New Spain; Local history; $17^{\text {th }}-18^{\text {th }}$ centuries

\section{INTRODUGGIÓN}

En el presente trabajo pretendo mostrar las posibilidades que ofrecen para el historiador las fuentes derivadas de las visitas canónicas de los obispos novohispanos, en concreto para los estudios de Historia local y regional. En efecto, la conexión del ámbito eclesiástico y secular en aquellos siglos hace que las visitas pastorales, sus fuentes documentales, sean útiles tanto para analizar aspectos de la vida de la sociedad o economía de la colonia como para el estudio de la Iglesia en la Nueva España. Por la función de la propia visita estos documentos nos hablan de localidades concretas, pequeñas y grandes y nos permiten acceder a lugares remotos del arzobispado y contemplar algunas de sus características y circunstancias.

Para Europa y en concreto para los territorios de la Península Ibérica existen investigaciones que utilizan las fuentes de las visitas episcopales para estudios locales. Desde propuestas de uso de estas fuentes y su valor (Mazzone-Turchini, 1990; Pueyo, 1993; Ansón, 1999) o estudios de poblaciones concretas utilizando visitas realizadas durante amplios periodos de tiempo (Arnal, 1990; Calderón, 1999; Cárcel y Trench, 1982; Calderón, 2000; Segado, 2016), hasta estudios demográficos de poblaciones pequeñas o de regiones enteras (Monjas, 1998). Para Indias el uso de estas fuentes es bastante más escaso. En las introducciones a las visitas que se han publicado, muchas veces se hace referencia a la posibilidad de ser utilizadas para estudios de tipo social, aunque en su mayor parte se refieren a la práctica religiosa (Garza y Pérez, 2007), centrándose a veces en una ciudad determinada (Salinas y Pozzaglio, 2017). Encontramos, sin embargo, algunos trabajos que emplean la visita canónica como fuente para estudios demográficos y tributarios (Pérez, 2011), o también para analizar la organización territorial y su gobierno (Palafox, 1997; Aguerre, 1999). Queda sin embargo mucho camino para aprovechar esta documentación en los estudios de áreas rurales que cuentan con poca documentación del ámbito secular.

Debido a la unión de las dos espadas -Corona e Iglesia- y su imbricación en

el gobierno de los territorios americanos, el clero participó en asuntos que hoy consideraríamos totalmente seculares " tal como el uso de sus padrones de fieles para 
el cobro de tributos de los indios o el reclutamiento de tropas. Las sedes parroquiales también fueron centros difusores de reales órdenes a través de los curas" (Aguirre, 2018, p. 2). Por tanto, la visita pastoral, la inspección de las parroquias del territorio episcopal, viene a ofrecer muchos datos sobre la vida y comportamiento de los pueblos y villas visitados.

La Corona, por concesión de la Santa Sede, tuvo parte en la delimitación de las diócesis, y en gran medida, pudo adaptar sus territorios jurisdiccionales a la organización político territorial. Sin embargo, la primera organización eclesiástica en orden a la evangelización llevada a cabo por los frailes y la posterior acción del clero secular, aunque se adaptó, por una parte, a las ciudades fundadas por españoles, por otra, aprovecharon la organización territorial previa, prehispánica, en la que estaba estructurada la población indígena. Así, en líneas generales las parroquias o doctrinas se instalaron allí donde se encontraba la cabecera del Señorío indígena y desde ella atendieron los llamados pueblos sujetos. Lógicamente esto varió con el paso del tiempo dependiendo del desarrollo económico y social de estas poblaciones, de sus variaciones de densidad poblacional y de las necesidades eclesiásticas o seculares. Ser cabecera, lugar de asentamiento de la parroquia fue algo deseado por la población indígena. Como señala Lilia López, "para esas comunidades la erección de la parroquia significó alcanzar un estatus social relevante, que se interpretaba como independencia social, ya que dejaron de ser sujetos de otro pueblo, y como posesión de riqueza, puesto que los residentes eran capaces de sostener una iglesia y a los curas" (López, 2008, p. 186).

Después de Trento, que reforzó la potestad episcopal como medio para llevar a cabo la reforma, "junto a la personalidad jurídica del obispo, la parroquia comenzará a ser la institución urbana y moral de la diócesis, organizándose con personalidad propia" (...), tendrá "función jurisdiccional, pastoral y económica" (Cárcel y Trench, 1982, p. 71). Será una institución importante por ser el lugar de contacto directo con la población pues el párroco era quien llevaba a la práctica los mandatos del prelado y los transmitía a la feligresía. En palabras de Rodolfo Aguirre las parroquias, por la amplitud de sus tareas pastorales y extra pastorales, se convirtieron en "las entidades más tangibles y cercanas a la vida cotidiana de los pobladores de Indias" (Aguirre, 2020, p. 1).

Siguiendo la Visita pastoral del prelado diocesano, entramos en las cabeceras y obtenemos también datos de los pueblos sujetos. El escribano nos informa de su densidad de población y de su vida en los aspectos que interesaba al obispo del lugar, desde las características climáticas y posibilidades económicas, hasta aspectos de la conducta de sus pobladores, como pueden ser los problemas en torno al matrimonio, al comportamiento en torno a la elección de pareja y los inconvenientes familiares o sociales que esto pudiera ocasionar. También las buenas o malas costumbres, las celebraciones, las capellanías y testamentarías que nos aportan datos sobre las personas importantes del lugar, o la práctica religiosa. Vemos actuar en algunos 
La visita pastoral como fuente privilegiada... - A. de Zaballa Beascoechea

casos a las autoridades indígenas y se pueden descubrir algunos aspectos de su organización local.

\section{LA VISITA EPISCOPAL}

Para comprender las posibilidades de las fuentes que ofrece esta institución es necesario conocer su funcionamiento y los documentos emanados de su actuación.

Como se sabe, la visita pastoral es una institución eclesiástica que tiene su origen en los inicios del cristianismo y que adquiere fuerza entre los siglos VI al XI quedando canonizada en los concilios de Tarragona (516), IV de Toledo (633) y II de Braga (572) que pasan al Decreto de Graciano (1142). Será a partir del siglo XV cuando comienza a tener fuerza la idea de reforma, y ya en este momento la visita no es vista sólo como un derecho del obispo sino como un deber, gracias a la normativa de los Concilios de Constanza (1414-18) y Basilea (1431-49), aunque no tendrá carácter de normativa obligatoria hasta el concilio de Trento (Miguel García, 1999).

El concilio de Trento llamó a los prelados a cumplir con esta obligación y dictó un conjunto de prescripciones sobre el sujeto, condiciones, tiempo y objeto de la visita. Fue una de las medidas implementadas para fortalecer la potestad de jurisdicción y gobierno de los obispos en sus diócesis. El objetivo era confirmar en la fe, asegurar la buena doctrina, corregir los errores, predicar el evangelio, e implementar soluciones para enderezar las malas prácticas o costumbres de cada parroquia. La visita, que podía hacerla el propio obispo o a través de un visitador delegado por él, será uno de los instrumentos fundamentales para llevar a cabo la reforma de las costumbres, tanto del clero como de los laicos y garantizar a lo largo del tiempo la correcta aplicación de las reformas del concilio.

En visita el obispo ejercía como pastor que quiere hacerse presente en las comunidades parroquiales, conocer personalmente a los fieles y que éstos le conozcan. Además, durante estas visitas recibía en directo las quejas, necesidades o denuncias de los feligreses de cada parroquia. De este modo a través del trato directo podía gobernar con conocimiento de causa, sin falseamientos o alteraciones de la información. En esta dirección van orientadas varias disposiciones tridentinas, como la obligación de residencia del obispo en su diócesis que era el único modo de poder cumplir con estos objetivos (Trento, Sesión VI, y Ses. XXIII).

El concilio de Trento llegó al detalle de la organización parroquial porque lo considero esencial para que la reforma que pretendía, llegara de verdad a todos los lugares. Así encomienda a los obispos que hagan lo necesario para que los párrocos puedan atender a todos los fieles: desde revisar la extensión del territorio parroquial, hasta la necesidad de ayudantes o vicarios para atenderlo ${ }^{1}$. Esta obligación de

1 “...manda el santo Concilio a todos los Obispos, que para asegurarse más bien de la salvación de las almas que les están encomendadas, dividan el pueblo en parroquias determinadas y propias, y 
considerar las necesidades de la organización parroquial y asegurarse de las buenas costumbres de los habitantes de todos los pueblos de su jurisdicción, por lejos que estuvieran, nos adentra en el ámbito local, en asentamientos a los que nunca hubiéramos llegado porque no fueron importantes ni a nivel episcopal ni tampoco para la administración real.

Los obispos debían realizar esta visita cada uno o dos años, aunque por la inmensidad geográfica de los obispados americanos, fueron pocos los que lograron visitar todo el territorio jurisdiccional durante su mandato. Es una documentación abundante que, como es lógico, es utilísima en primer lugar para analizar y conocer a fondo el gobierno de la diócesis, pero, al mismo tiempo, dependiendo de los intereses del obispo, también contiene información sobre las características geográficas, la dedicación económica de la población, su densidad, la organización política, etc. No son datos obligatorios, como podrían exigirse en una Descripción geográfica con cuestionario fijo, pero se encuentran en muchos de los Libros de visita.

Esta documentación se debería encontrar en primer lugar en los archivos de las diócesis correspondientes, en concreto en la secretaría episcopal de cada prelado, por derivar de la actuación del obispo. También en el Archivo de Indias por ser el Consejo de Indias el receptor de los informes de visita y en ocasiones de la relación completa de la misma. Sin embargo, los archivos eclesiásticos mexicanos han sufrido bastantes calamidades por las guerras del siglo XIX y las revoluciones del XX. Durante la revolución mexicana a inicios del siglo $\mathrm{XX}$, muchos de ellos fueron expoliados por el Estado, otros se intentaron defender trasladando sus fondos a otros lugares. Todo esto llevó a la pérdida de documentación, y al traslado de parte de esos fondos a otros archivos. En concreto, los fondos correspondientes al Archivo Histórico del Arzobispado de México se encuentran divididos entre el archivo diocesano y el Archivo General de la Nación (Watson-González-Bravo, 2002). Este es también el caso de los archivos de Oaxaca y Michoacán que encontramos divididos entre archivos estatales y eclesiásticos.

Un caso especial es el Archivo de San Cristóbal de las Casas, correspondiente a la diócesis de Chiapas. Además de algunas pérdidas debidas a los traslados para evitar su robo o destrucción, la desgracia le vino de quienes estuvieron al frente del archivo desde los años 80 hasta el año 2007, dependientes del Instituto de Asesoría Antropológica para la Región Maya. Este directivo tomó una decisión que causó -y sigue causando- mucha controversia y que fue la de ordenar todos los documentos por pueblos y, dentro de cada uno, de acuerdo con una larga lista de temas y subtemas.

asignen a cada una su párroco perpetuo y particular que pueda conocerlas, y de cuya sola mano les sea permitido recibir los Sacramentos; o den sobre esto otra providencia más útil, según lo pidiere la calidad del lugar. Cuiden también de poner esto mismo en ejecución, cuanto más pronto puedan, en aquellas ciudades y lugares donde no hay parroquia alguna; sin que obsten privilegios ningunos, ni costumbres, aunque sean inmemoriales" (Trento, Ses. XXIV, decreto reforma, c. XIII). 
La visita pastoral como fuente privilegiada... - A. de Zaballa Beascoechea

El motivo sería facilitar a los habitantes de la zona la consulta de su pasado, así como la investigación de los antropólogos.

"Este cambio supuso reorganizar todos los documentos y mezclar expedientes que provenían de los diferentes archivos, dificultando de manera extrema estudiar la historia de la institución misma que había generado toda esa documentación. Así, hoy día, por ejemplo, la visita pastoral está dispersa en las carpetas de los diferentes pueblos visitados, de forma que es casi imposible tener una idea de conjunto de la visita misma." (López-Viqueira, 2019, p. 8).

De los tres grandes archivos (México, Puebla y Guadalajara), el de Guadalajara, a pesar de sufrir tres saqueos, se ha conservado en buen estado y casi completo, y lleva mucho tiempo abierto al público. El Archivo histórico de la archidiócesis de Puebla es quizá el mejor conservado. En la actualidad está en catalogación a través de un convenio con la Universidad de las Américas de Puebla aunque está cerrado para los investigadores.

Los documentos derivados de la visita son los siguientes:

1. El Diario o Libro de visita

2. El auto de visita de cada parroquia

3. Los procesos seguidos durante el recorrido y los enviados a la curia

4. El informe final que el prelado debía enviar a la Corona

5. Y otros documentos como las ordenanzas, mandatos, etc. que, como es lógico dependía de la voluntad de cada obispo

Me centraré en el libro de visita que recoge la actividad diaria del obispo durante el recorrido; su horario, reuniones, administración de sacramentos y celebraciones litúrgicas, licencias concedidas a clérigos y laicos, la revisión o visita de los lugares sagrados, etc. Se incluye así mismo, el auto de visita dictado por el obispo para cada parroquia, y para cada una de sus cofradías visitadas, con lo que debían corregir o mejorar. Cada prelado podía organizar la visita según los temas que consideraba de mayor interés dentro de los objetivos generales que eran la confirmación en la fe y la reforma de las costumbres. Como se sabe podía ser visita general o particular dependiendo, no del recorrido sino de los temas que deseara revisar durante el mismo.

Lógicamente las fuentes de visita deben cruzarse y completarse con otras fuentes dependiendo del objeto de la investigación. Entre la documentación que deriva de la visita canónica, puede ser útil acudir al informe final enviado al Consejo de Indias pues puede confirmarnos si ciertas características son algo exclusivo de la región que interesa investigar o es algo común a todo el obispado; estoy pensando, por ejemplo, en el empeño por la enseñanza del castellano a los indios, su resistencia, o no, a aprender la nueva lengua, etc. 
Para el presente estudio he utilizado seis visitas de los siglos XVII y XVIII: Mota y Escobar (1609-1617, Puebla), Palafox y Mendoza (1643-1646, Puebla), Juan de Santiago de León Garabito (1678, Guadalajara), Francisco Aguiar y Seijas (16831688, México), José Lanciego y Eguilaz (1715-1722, México), Pedro Tamarón y Romeral (1764-1768 Durango). Son Diarios muy dispares en su extensión y en los asuntos a los que se dedica atención en el Diario.

Paso a revisar algunos temas locales susceptibles de ser investigados con las visitas pastorales como fuente, con ejemplos de algunos estudios ya realizados y otros que se sugieren.

\section{ORGANIZACIÓN TERRITORIAL DE LOS PUEBLOS INDÍ- GENAS, DEMOGRAFÍA Y GOBIERNO}

\subsection{Organización territorial}

Como hemos señalado más arriba Trento encomendó al obispo que asegurara la atención de los fieles comprobando la adecuada organización parroquial. Sin embargo, no fijó un criterio único de organización, dejando al arbitrio de los prelados señalar la jurisdicción parroquial teniendo en cuenta el territorio de cada curato o el número de fieles que correspondían a cada uno independientemente de su extensión territorial. Lo que le interesaba alcanzar era que la cura de almas en las parroquias fuera eficaz y estuviera bien organizada localmente. Merece la pena reproducir los consejos del concilio:

“...manda el santo Concilio a todos los Obispos, que para asegurarse más bien de la salvación de las almas que les están encomendadas, dividan el pueblo en parroquias determinadas y propias, $\mathrm{y}$ asignen a cada una su párroco perpetuo y particular que pueda conocerlas, y de cuya sola mano les sea permitido recibir los Sacramentos; o den sobre esto otra providencia más útil, según lo pidiere la calidad del lugar. Cuiden también de poner esto mismo en ejecución, cuanto más pronto puedan, en aquellas ciudades y lugares donde no hay parroquia alguna; sin que obsten privilegios ningunos, ni costumbres, aunque sean inmemoriales"(Trento, Ses. XXIV, decreto de reforma, cap. XIII).

Como señala Teresa Álvarez Icaza, ya desde el inicio de la evangelización, los mendicantes en México se asentaron en las cabeceras prehispánicas y al tener que compartir dicho territorio con otros frailes o con los seculares "fue común que la competencia entre las órdenes y de los regulares con los seculares se diera en los pueblos sujetos; esto se conjugaba con el deseo de autonomía de los vecinos de los pueblos menores" (Álvarez Icaza, 2011, p. 502).

Algunos de los pueblos sujetos llegaron a alcanzar el estatus de cabecera debido a su crecimiento demográfico o actividad comercial. Es decir, realmente 
hacía referencia a un aumento de su importancia en varios aspectos. Desde el punto de vista eclesiástico esto se concretaba en la construcción de una iglesia digna y en la presencia del cura para residir en dicha localidad convertida en parroquia.

En diferentes visitas pastorales se comprueba la supresión o creación de parroquias y los motivos para dividirlas. Esto se ha analizado muchas veces desde el punto de vista eclesiástico, para estudiar los conflictos entre el clero regular y los seculares, pero no se ha utilizado para investigar la estructura, evolución y organización de la población indígena y sus autoridades, pues junto a la modificación eclesiástica corría muchas veces el cambio político.

Un ejemplo de este tipo de estudio es el que realiza Bernardo García Martínez en su introducción a las visitas de Palafox entre los años 1643-1646 (Palafox, 1997, pp. XIX-XLI). Explica que lo que se califica como "pueblo" en el Diario, se refiere en la mayoría de los casos a la realidad contenida en el término nahua de "altepetl" es decir a una unidad corporativa que podríamos denominar señorío o estado, y que conservó sus características esenciales en época colonial. De hecho, demuestra cómo se utilizó el altepetl como base para la fundación de parroquias o doctrinas. En la anotación del Diario de visita palafoxiano, indica la relación entre cada una de las parroquias con el correspondiente altepetl, así como a la organización de la administración española sobre el territorio. De esta forma se puede apreciar el mantenimiento o no de la organización prehispánica, sus características, extensión, etc. A pesar de los evidentes cambios tras la conquista y asentamiento de los españoles, estas entidades prehispánicas mantuvieron su personalidad, razón por la que se intentó esa correspondencia entre altepetl y parroquia, y la aprobación del cacique en cuanto a la constitución de dicha parroquia, pues el cacique tenía jurisdicción sobre el territorio correspondiente y sobre sus habitantes. Llevaba el padrón de tributarios ya existente en el periodo prehispánico.

En ocasiones, como dice Aguirre, la creación de una nueva parroquia proviene del "interés de muchas haciendas del arzobispado por la fundación de nuevas cabeceras parroquiales, cercanas a ellas y que atendieran las necesidades espirituales de sus trabajadores, cada vez en aumento, causando inquietud en los curas por la despoblación que paralelamente se producía en los pueblos". (Aguirre, 2008, p. 490). Podríamos añadir para el tema que nos interesa, que causaría también preocupación entre las autoridades indígenas de dichos pueblos que verían descender su poder. Así, en muchos casos la economía -el crecimiento de producción de una hacienda y, por tanto, el número de trabajadores- llevó también a la variación de la localización de las parroquias, o una nueva creación y esto afectaría directamente a los núcleos de población indígena.

Todo esto da luces para advertir la importante información que podemos encontrar en la documentación de visita sobre la región o localidad que investiguemos: conocer cambios de relevancia del pueblo, su gobierno, desarrollo económico y 
demográfico, el mestizaje de determinados poblados, etc. Utilizando varias visitas de un determinado lugar podríamos seguir la evolución de sus núcleos de población. A lo largo del XVIII se lleva a cabo la secularización de las doctrinas llevadas por religiosos, actividad que acarreó en muchos casos la división de parroquias y también de jurisdicciones. Puede ser interesante, por tanto, el análisis de dicha secularización, para los estudios locales pues, por una parte, ofrece datos sobre muchas localidades y por otra, el contexto adecuado de los posibles cambios y divisiones.

En efecto, uno de los cambios importantes a mediados del XVII fue el crecimiento de los ingenios y haciendas que provocó el despoblamiento de algunos altepetl y la conversión de estas haciendas en centros de población. De este modo, el Diario de visita de Palafox ha sido la base para reconocer estos pueblos, su personalidad y su relación con otros lugares de su entorno, comprobando la personalidad, dependencia o sujeción a otras corporaciones o instituciones.

Se comprueba también en el arzobispado de México durante la visita de Aguiar, la existencia de grandes haciendas que funcionaban casi como parroquias, al menos como una extensión de la misma, en las que sus trabajadores recibían todos los sacramentos, llegando a tener hasta la procesión de semana santa. Es el caso de San Andrés de Mixquic en el arzobispado de México (Archivo General de la Nación. México, Indiferente virreinal, volumen 1460, expediente 35. Cuarta visita de Francisco de Aguiar y Seijas, 1686-1687, 15 marzo de 1687, Doctrina de San Andrés Mixquic). Si consultamos el padrón que nos ofrece la misma fuente, esta hacienda contaba con 370 habitantes. También en el norte del virreinato, en el obispado de Durango, Pedro Tamarón y Romedal, en su visita al pueblo de Santa María de las parras en junio de 1777, nos dice que "en dicho día se visitaron los tres libros parroquiales pertenecientes a la hacienda de Patos, que presentó el bachiller don Phelipe Ruiz de Guadiana, teniente de cura de aquel ramo" (Tamarón, 1997, p. 127). Es decir, se trata de la capilla de una hacienda que cuenta con sus propios libros de sacramentos y un teniente de cura dedicado a ella.

En la visita que realiza José Lanciego Eguílaz al arzobispado de México en los inicios del XVIII el beneficiado de San Juan del Río solicita la división de la parroquia. Se trataba, en efecto, de una parroquia grande que atendía, además de la cabecera, ocho barrios y cinco pueblos sujetos, 43 haciendas y ranchos de todo tamaño. El total de feligreses es de 7928 (Aguirre, 2016, p. 68). En este caso la hacienda más grande tenía 727 feligreses, una cantidad importante para variar el estatus o importancia de otras unidades de población. La importancia que adquieren estas haciendas de cara a la atención pastoral evidencia que adquirían peso como núcleos de población y variarían a la larga la organización de los habitantes de la región.

Bernardo García hace un análisis muy interesante de estas haciendas (Palafox, 1997, p. XXXVII) al considerarlas como lugares informales, desde el punto de vista político, pues, aunque se encontraba dentro de los límites de un altepetl, 
realmente estaba fuera de su autoridad; se podría considerar como una situación de extraterritorialidad. Su fundamento era la propiedad de la tierra pero son centros de población y como tales son visitados por el obispo. En principio, la atención espiritual dependía de la cabecera del altepetl pero con frecuencia por la distancia o la densidad de trabajadores, se acababa estableciendo una atención religiosa propia.

La organización prehispánica puede rastrearse en la visita que hizo años antes a este mismo obispado el obispo Mota y Escobar. En el "pueblo" de Chamatlán (Chumatlán, Veracruz) por razones puramente pastorales, Mota tenía intención de unir esta parroquia a otras dos -Cuahuitlan y Mecatlan- que eran del mismo encomendero, pero al preguntar a los principales se encontró con una negativa que no ofrecía duda: "dijéronme, que no les pasaba por (el) pensamiento; (...); de cuya causa, y por no inquietar a los indios, lo dejé estar como estaba, por ahora" (Mota, 1987, p. 70). En efecto, Bernardo García nos informa que (Palafox, 1997, p. 112, nota 94) este pueblo era, como los otros dos, cabecera de altepetlt y no consentirían perder su calidad de parroquia y supeditarse o depender de otro, aunque sólo fuera en lo eclesiástico.

Además, gracias a los padrones que los párrocos debían entregar al visitador, se puede estudiar la densidad de población y la proporción de las diferentes calidades pues se indicaba el número de españoles, indios, negros, mulatos o mezclas, y no únicamente del pueblo de la parroquia sino de todos los territorios anejos.

Así mismo, se aportan datos interesantes para analizar las posibilidades económicas de los territorios, como la geografía de la jurisdicción episcopal, sus posibilidades económicas, y a veces la dedicación de la tierra. Lógicamente el detalle y aspectos de la información depende del obispo y del notario que escribe el Diario. De las que he revisado es especialmente significativa en este sentido la de Mota y Escobar, que en cada pueblo al que entra nos ofrece datos como los que siguen:

"Tiene 270 tributarios casados sólo en la cabecera. Es del temple que ya toca caliente, tiene buena agua; la granjería de los indios es maíz, aves y fruta de la tierra, chile, miel virgen, que todo lo llevan a vender al puerto de S. Juan de Ulúa (San Juan de Ulúa en el puerto de Veracruz) que dista de aquí 2 leguas con lo cual viven sin necesidad" (Mota, 1987, p. 44).

Con los datos de los padrones que presentan los párrocos Manuel Pérez Zeballos ha estudiado la organización de la población indígena y el control de tributos, tipos de trabajos en diversas regiones, su organización territorial o las condiciones de vida. Así mismo aporta información valiosa para la investigación de la demografía de una determinada región o provincia de época colonial. Son datos que Pérez Zeballos ha combinado con las visitas seculares y las Descripciones geográficas de la región de la Huasteca (Pérez, 2011). 


\subsection{El gobierno local}

La documentación derivada de la visita es también útil para investigar sobre el gobierno de los diferentes asentamientos. Gabriela Ramos está iniciando una investigación muy interesante (Ramos, 2019) en la que, a través de los informantes que en cada pueblo respondían al cuestionario del visitador del arzobispado de Lima, analiza las características de sus líderes: la cultura, alfabetización y continuidad de los curacas en la sierra del Perú.

No he encontrado ninguna investigación parecida para la Nueva España, pero sí se puede decir que existen pistas en las fuentes pastorales novohispanas para analizar el gobierno local de los pueblos de indios. En efecto, al revisar los Diarios de visita además de hablarnos de los cargos que reciben al obispo o arzobispo, y algunas de sus funciones, se detallan determinados problemas en los que ellos participan o las acciones de estas autoridades en relación al obispo.

En las fuentes de los arzobispos Aguiar y Lanciego, se llegan a anotar los nombres y composición del cabildo indígena de ciertas localidades a raíz de peticiones, denuncias o quejas realizadas por los gobernantes de estos pueblos al arzobispo. Por ejemplo, Aguiar lo explicita cuando éstos indios solicitan la fundación de una cofradía:

"habiendo comparecido don Juan Nicolás gobernador del pueblo de Tuxpa sujeto de este beneficio por sí y en nombre de Pedro de Santiago y Juan Lucas alcaldes, Pedro Gerónimo fiscal Juan Pablo y Nicolás García regidores, don Pedro González, don Mateo Jacobo, don Gabriel de la Cruz, José Nicolás y don Diego Nicolás principales de dicho pueblo y pedido se les funde una cofradía de la advocación de nuestra señora de la Concepción para su consuelo...”. ( Pastoral Box 14, Henry Albert Monday Collection Relating to Mexico, Manuscript Division, Library of Congress, Washington, D.C. Photo by Benjamin Reed, Quinta visita de Francisco de Aguiar y Seijas, 26 diciembre 1687, pueblo de Tuxpa).

Estos datos se insertan en otras ocasiones por conflictos entre pueblos y, a veces, no sólo se incluyen los miembros del cabildo indígena del momento sino también de quienes ostentaron estos cargos en el periodo anterior y que claramente siguen contando con cierta preminencia. Se hace frecuente referencia a los cargos indígenas porque los prelados contaban con estas autoridades para ciertas actividades pastorales: desde la creación del maestro de castellano, hasta para lograr que los indios acudieran a escuchar la doctrina o decidir, junto con el cura, si un trabajo era tan urgente como para dar permiso de que se realizara en domingo (Aguirre, 2016, p. $18,208,327,334,339,361,382,421,466,478 \ldots)$. 


\section{ACTIVIDAD DE LAS COFRADÍAS, SU ECONOMÍA Y GOBIER- $\mathrm{NO}$}

La información sobre cofradías incluida en el Libro de visita es también interesante para los estudios locales, pues no era infrecuente que los mayordomos y otros cargos de las mismas, fueran ocupados por los miembros del cabildo municipal si era cofradía de indios, o por algún personaje importante entre los españoles, si eran ellos quienes la habían fundado. Siempre se recoge el nombre del mayordomo y muchas veces de quién le había precedido en el cargo. De manera que podemos localizar con estos datos a parte de la élite local.

En el caso de las cofradías de indios, las inspecciones de estas instituciones suponían una información adicional sobre propiedad de tierras y ganado, así como otras posibles pertenencias (Martínez, 1977). Dorothy Tanck recuerda que, así como el establecimiento de una cofradía era de jurisdicción episcopal, así sus bienes eran considerados eclesiásticos y por tanto inalienables y sin obligación de tributar. Debido a que muchas de estas cofradías estaban en manos de los indios sin el control del sacerdote, se utilizaron para el control de las cajas de comunidad donando parte de su contenido a las cofradías desde donde manejaban el monto. Son las llamadas cofradías de pueblos de indios (Tanck, 2004).

A lo largo de la visita, al inspeccionar el funcionamiento de las cofradías y hermandades, se recogen muchas veces las cantidades que éstas recibían cada año y en qué se gastaban dichos ingresos. Los bienes y cuentas de cofradías eran uno de los "dominios" eclesiásticos que la Corona quiso acaparar en el XVIII pues consideró que con él dominaba parte de la economía local y sobre todo, sumaba autoridad sobre la población indígena. Fue uno de tantos medios para descorporativizar las comunidades indígenas. Se comenzó solicitando impuestos y concluyeron enajenando los bienes y capitales de estas instituciones (Zaballa-Lanchas, 2017, pp. 97-103).

El obispo, en efecto, revisaba el funcionamiento de la cofradía, sus constituciones y cómo se observaban, así como su economía: ingresos y gastos, bienes muebles e inmuebles. Así mismo, la cantidad que había en ese momento en la caja y los deudores. Según lo visitado, se asentaban los aspectos a mejorar si habían encontrado desajuste en las cuentas o claramente robo. Evidentemente los prelados encontraron muchas cofradías pobres que no tenían casi ni qué dinero justificar, pero, dependiendo de los pueblos y villas, también las hubo con muchos bienes.

Como sucede con los demás asuntos, es muy desigual la atención prestada a estas instituciones por unos obispos u otros; desde los que, como Palafox, casi se ciñen a indicar el número y si son de indios o españoles hasta la detallada lista de bienes por parte de Tamarón y Romedal. Pero siempre se pueden encontrar Diarios con datos interesantes. 
Es Francisco de Aguiar y Seijas, en su visita hacia el sur del arzobispado, quien al tomar cuenta a una cofradía de Texupilco registra que los indios declararon

"las doscientas y cincuenta y dos reses chicas y grandes que así tiene dicha cofradía por sus bienes y de las sesenta y ocho bestias caballares teniendo cuidado de que cada año se cuente dicho ganado y lo que fructificaren y lo que hubiere de aumento para que con su intervención se entregue al mayordomo que le sucediere y en esta forma de unos a otros mayordomos y mandó que si conviniere el venderse parte del ganado o bestias, sea con intervención del dicho beneficiado para que su procedido se emplee en cosas útiles para el culto divino o el adorno de su iglesia y no en otra forma (...) y al pie del cabildo de elección se pondrá el inventario de todos los bienes, alhajas y preseas que tuviere dicha cofradía y del dicho ganado y bestias y su aumento para que se haga cargo el mayordomo que se eligiere y en este libro se asienten los hermanos de dicha cofradía". (Archivo Histórico del Arzobispado de México, Secretaría arzobispal, Visitas, CL 19, L 1. 2 ${ }^{\mathrm{a}}$ visita de Aguiar y Seijas, 16 febrero, 1685, pueblo de Texupilco)

En estas anotaciones se nota la insistencia -repetida en otros muchos pueblosde contar el ganado, llevar cuenta del crecimiento del mismo, así como de posibles ventas. Existe una actividad ganadera que lógicamente procuran acrecentar, pero de la que el obispo no quiere perder el control e insiste una y otra vez en la presencia del beneficiado en todo ello. Estaba claro que no siempre se informaba al cura de las cuentas de la cofradía ni del uso de sus bienes o la venta de ganado y no fue infrecuente el fraude por parte de los mayordomos.

En varios obispados existían cofradías con importante patrimonio. En el obispado de Durango, por ejemplo, Pedro Tamarón y Romedal, mandaba anotar con detalle los bienes de las cofradías. Así, en el pueblo de San Juan del Río examinó una cofradía de españoles dedicada a las Benditas Ánimas del Purgatorio que contaba con 2100 pesos a réditos en haciendas y tierras de labor, así como una casa pequeña de la que se obtenían algunos pesos cuando se alquilaba (Tamarón, 1997, p. 21) o los bienes de una hermandad en San Joseph y Santiago del Álamo que contaba con una huerta con 7000 cepas y 14 parrones de frutales (Tamarón, 1997, p. 113). En otras ocasiones se declaran como bienes dos viñas con sus casas para los cuidadores de dichas viñas... y otro pedazo de tierra que compró el mayordomo dicho año que ha plantado de cepería nueva (Tamarón, 1997, p. 128-129). Como se ve son propiedades importantes que podían tener muchos frutos y que nos hablan de la actividad de estos pueblos.

Por esos mismos años en el arzobispado de Guadalajara, tierra ganadera, el obispo don Juan de Santiago y León Garabito, recorría su territorio en visita general. Quizá porque hacía mucho que no se había realizado visita episcopal dice encontrar en "desorden" los asuntos de su jurisdicción. Respecto a las cofradías, descubrirá algunas muy pobres y otras con bastantes bienes. Así, En diciembre de 1678 cuando realiza su visita a Ahuacatlán, revisa la cofradía de Nuestra Señora de la Concepción, 
del pueblo de Camotlán. Podríamos considerarla rica pues contaba con abundantes objetos para la celebración de sacramentos así como objetos de plata y alhajas en su capilla. Pero además dicha cofradía era propietaria de considerable cantidad de ganado: "El ganado vacuno ascendía a 600 reses de hierro para arriba y 80 bestias caballares, habiendo dispuesto que al herradero asistiera el Cura doctrinero" (Santiago y León, 2009-2010, agosto de 2009). Este nivel de bienes se repite en el hospital de Zapotlán que contaba con un patrimonio que ascendía a 680 reses más otros animales (Santiago y León, 2009-2010, diciembre de 2009).

Es lógico, por tanto, que estas corporaciones tuvieran sus propias inversiones y participaran en la economía de la zona. Nos puede servir como ejemplo una cofradía de Tepic, en el actual estado de Nayarit: "daba sus primeros pasos la Cofradía del Santísimo Sacramento, recién fundada, cuyo patrimonio ascendía a 4.090 pesos en efectivo, que el obispo determinó se invirtieran en 'fincas seguras', y 1100 asegurado en vales, que se dispuso fueran cobrados cuanto antes. El ganado de esta hermandad ascendía a 246 becerras y doce potros" (Santiago y León, 2009-2010, diciembre de 2009).

A principios del XVIII cuando el arzobispo Lanciego visita las cofradías de su territorio, nos informa de que algunas cuentan con bienes raíces y muebles, tienen sus reses arrendadas, y controlan aspectos como el caporal encargado del ganado, el herradero y el control de las pieles del "becerraje" y "toraje". Datos que hablan de la actividad de la población y del manejo de bienes, además de nombrar a sus mayordomos y en ocasiones a los gobernadores o alcaldes del lugar. (Aguirre, 2016, pp. 292, 666, 718-719, etc.).

Pero estas corporaciones no sólo nos dan cuenta de la riqueza o pobreza de ciertas comunidades indígenas, también nos ayudan a descubrir las consecuencias de la aparición de reales de minas o grandes haciendas en los asentamientos indígenas. Así, llama la atención la jurisdicción de Hostotipaquillo, cercana a varias minas, en la que los mayordomos y priostes de la cofradía de nuestra Señora de la Concepción,

“dijeron no tenían forma de cuentas porque los que habían sido mayordomos y prioste habían sido todos los más forasteros, porque el pueblo no se componía más que de cuatro indios, y esos estaban ocupados en otros ejercicios y que como forasteros, los que no habían muerto se habían ido a sus pueblos, mas que estaban entendidos no deberían cosa ninguna a la cofradía por no tener bienes, y las limosnas cortas, que aún no alcanzaban a los cortos gastos que tenían en la dicha cofradía". (Santiago y León, 2009-2010, Abril 2009).

Es decir, se trataba de una localidad con población flotante que aún así conformaron una cofradía. Habría que averiguar si existió un pueblo anterior al real de minas, si se trató de un traslado de población, o únicamente trabajadores temporales de los que algunos permanecieron como residentes fijos. 
En ocasiones las cuentas de cofradías dan noticia del efecto de las epidemias. Es el caso de los cofrades del hospital de Nuestra Señora de la Concepción del pueblo de Sentispac, quienes al solicitarles explicación de las cabezas de ganado que había registrado la cofradía en la anterior visita pastoral, declararon que los anteriores cofrades "murieron en una peste que hubo. Murieron muchos de los naturales del pueblo y no pudieron cuidar de él [ganado] y se les alzó". Les pidió el obispo recobrar lo que pudieren de dicho ganado y lo hicieran rodeo, es decir, lo domesticaran de nuevo, para regenerar su patrimonio"( Santiago y León, 2009-2010, marzo de 2010).

También pueden encontrarse datos sobre los principales del lugar en la información sobre testamentos, así como en la fundación de capellanías, pues es frecuente que se indique su fundador y cuál fue el monto.

\section{MATRIMONIOS Y MESTIZAJE}

A lo largo de la visita el obispo ejerce su potestad como juez, tanto para dirimir asuntos de denuncias que se resolvían in situ, de los que a veces queda rastro en el Diario, como otras de mayor envergadura que muchas veces remite al tribunal de la sede episcopal; se refleja también el ejercicio de su jurisdicción en lo relativo a los sacramentos. En este sentido el obispo, actúa como juez durante este recorrido solventando en el momento las licencias o diligencias matrimoniales, las dispensas solicitadas o las correcciones y penas.

Dependiendo del prelado se registran en el Diario las licencias y dispensas otorgadas in situ, o incluso, como es el caso del arzobispo de México Aguiar y Seijas, se recogen también los informes matrimoniales de dichas licencias. En efecto, el arzobispo de México guardó en su secretaria todas las licencias de matrimonio que había dispensado a lo largo de las cinco salidas de su visita general entre 1683 y 1688. Esto supone una información preciosa sobre la práctica del matrimonio en todo el territorio visitado a lo largo de cinco años. No es una fuente cuantitativa pero si de valor representativo, pues se trata de una muestra del comportamiento de esa población que al paso del obispo por su localidad solicitan que los case o que les dispense algún impedimento para poder hacerlo. Esta fuente se ha mostrado muy rica para estudiar, por ejemplo, el mestizaje de la población colonial en el arzobispado mexicano, mestizaje tanto en la elección de pareja, como en las relaciones laborales (Zaballa, 2016).

Hay que tener en cuenta que las diligencias matrimoniales llevaban consigo la entrevista con los contrayentes, su declaración de estar libres de otro compromiso y de cualquier impedimento para casarse. Nos informan de los datos de los contrayentes y de sus padres, de su lugar de origen y su residencia actual. Además, se entrevistaba a testigos de ambas partes y de éstos se recogían datos tan interesantes como, profesión, edad, calidad racial, origen y residencia. Es decir, no son los escuetos 
datos que aparecen en el libro de sacramentos de la parroquia. Hay que resaltar que estas informaciones matrimoniales resultado de la visita, se expidieron en un lapso breve de tiempo, cinco años, y por tanto, estamos ante individuos de una misma generación entre quienes coincidirían similares dinámicas sociales.

Gracias a toda esta información, lógicamente contrastada, se puede conocer, el porcentaje de matrimonios mestizos, no solo entre indios y españoles sino también de estos con negros, mulatos y mestizos. Se pueden indagar las relaciones laborales entre individuos de diferentes calidades pues en la información matrimonial se incluye la profesión de los testigos, se indica, si es el caso, en qué hacienda trabajan de manera que nos encontramos, por ejemplo, que españoles, indios o mulatos compartían la misma profesión: barreteros de mina, oficiales, propietarios de mulas o que trabajan en la misma hacienda. Se descubre así que, en muchos de esos casos, el español no está socialmente por encima del indio y este del negro o mulato, pues pueden ser todos ellos empleados de un mismo minero o propietarios y comerciantes de idéntico nivel; se llega a dar el caso de que el enlace entre un indio y una española no supuso ascenso social para el indio sino para la española que servía en una hacienda.

También se alcanza a descubrir las migraciones por trabajo de muchos de estos cónyuges y de sus amigos y colaboradores presentados como testigos. Llama la atención, de hecho, la alta movilidad de los contrayentes. En efecto, las informaciones permiten conocer los cambios de ciudad porque entre los datos que obligatoriamente debían contener era imprescindible indicar el lugar de nacimiento de los contrayentes, el lugar de residencia del momento de la solicitud y, especialmente, cuánto tiempo llevaba viviendo en su último destino. Estos mismos datos los ofrecen para los testigos, añadiendo desde cuando conocen a los novios. Todo esto para que el beneficiario pudiera asegurar que no existían impedimentos, pues era relativamente frecuente que los indios intentaran ocultar la bigamia u otro motivo de ilicitud a través del cambio de localidad.

Así, estas fuentes permiten descubrir flujos poblacionales diversos. Por una parte, se observan migraciones del campo a la ciudad en busca de mejores posibilidades de vida, por ejemplo, a Querétaro desde Tequixquiac, desde pequeños pueblos a centros mineros, como Pachuca, Real del Monte etc. Pero también se comprueba la migración a los reales de minas desde ciudades como México o Puebla (Zaballa, 2016).

Estos datos nos llevan a corroborar que los naturales no formaban un universo rígido. Por una parte, los indígenas que aparecen en dichas licencias matrimoniales, pertenecían a diferentes grupos sociales, desde indios con cargos en el cabildo, maestros u oficiales de diferentes oficios artesanales, cargos de Iglesia, etc., hasta, algo más numerosos, los pertenecientes a niveles inferiores. En las licencias que comentamos, la mayoría de los casos, ocupa lugares intermedios cuyos miembros ejercían actividades variadas; desde arrieros con mulas propias a maestros u oficiales artesanos; actividades que fueron compartidas con españoles y castas. 
Se puede completar esta información con otras licencias y procesos seguidos durante el recorrido episcopal. Los más abundantes se refieren al entorno de la vida matrimonial: amancebamientos, adulterios, dispensa de grados de consanguinidad, pero también se presentan pleitos entre indios y curas, denuncias, petición de informes de calidad y buenas costumbres, etc. Así dentro del libro de gobierno, en el apartado "Autos ordinarios, criminales y de testamentos fechas en las visitas que hizo el arzobispo...", se recoge la relación de todos los procesos que el obispo siguió durante la visita, también de aquellos secretos que no se recogen en el Diario. Encontramos algunos muy interesantes relativos al matrimonio, como la exigencia de hacer vida maridable, malos tratos, incesto, incontinencia o adulterio. Información toda ella interesante para ser utilizada para un estudio local

\section{CONSIDERACIONES FINALES}

Con el recorrido hecho por algunos Diarios de visita y otras fuentes derivadas de la misma, considero que se ha abierto un panorama de las posibilidades que ofrecen las fuentes eclesiásticas y en concreto las derivadas de la visita eclesiástica, para el estudio de los poderes locales y regionales, así como algunos métodos de análisis. En la actualidad existe un interés creciente por esta actividad episcopal y la localización de estas fuentes, así como su publicación. Estas publicaciones pueden ser de gran utilidad a los estudiosos de localidades y regiones concretas.

Por tratarse de una documentación que recoge el recorrido por un territorio concreto, paso a paso, aportando datos sobre localidades de todo tamaño e importancia, es de especial interés para los estudios locales. Pienso que ha quedado claro, el tipo de información que puede buscarse para temas tan diversos como la organización territorial o las costumbres matrimoniales, poderes locales o posibilidades económicas de una determinada región. También se ha reflejado la irregularidad de estas fuentes dependiendo del autor: la variación de intereses de un obispo a otro puede cambiar completamente el contenido de los Diarios de visita o de los demás frutos del recorrido episcopal.

He comenzado analizando las posibilidades de esta documentación para el estudio de la organización territorial y gobierno local. Razones de las nuevas delimitaciones territoriales de antiguas unidades de poder prehispánico, así como del gobierno local, las relaciones de estos cargos con la organización eclesiástica y su evolución en el nuevo cabildo indígena.

Entre los obispos consultados para el presente artículo hay varios que aportan bastantes datos de tipo económico, tanto de la actividad económica o comercial de la población allí asentada, como de las posibilidades del territorio. Nos hablan de los productos agrícolas o ganaderos, o incluso de la producción artesanal. Siempre se trata de fuentes parciales que deben ser completadas o contrastadas con otras, pero que sirven para aportar luces desde otro punto de vista. 
La visita pastoral como fuente privilegiada... - A. de Zaballa Beascoechea

\section{FUENTES EMPLEADAS}

\subsection{Archivo}

Archivo Histórico del Arzobispado de México, Secretaría arzobispal, Visitas, CL 19, L 1, fols. 213r-695r. Segunda visita del arzobispo Francisco de Aguiar y Seijas. Visita al sur del arzobispado de México, 1684 - 1685.

Archivo General de la Nación. México, Indiferente virreinal, volumen 1460, expediente 35. Cuarta visita de Francisco de Aguiar y Seijas, 1686-1687.

Pastoral Box 14, Henry Albert Monday Collection Relating to Mexico, Manuscript Division, Library of Congress, Washington, D.C. Photo by Benjamin Reed. Quinta Visita de Francisco Aguiar y Seijas 1687-1688

\subsection{Bibliografía}

Aguerre Core, Fernando (1999). La visita general de la diócesis del Paraguay realizada por el illmo. D. Manuel Antonio de la Torre (1758-1769). Revista complutense de Historia de América, n. 25, pp. 111-138.

Aguirre Salvador, Rodolfo (2008). La secularización de doctrinas en el arzobispado de México: realidades indianas y razones políticas, 1700-1749. Hispania Sacra, n. LX pp. 487-505. DOI: https://doi.org/10.3989/hs.2008.v60.i122.65

Aguirre Salvador, Rodolfo (coord.) (2016). Visitas pastorales del arzobispado de México, 1715-1722. México: Instituto de Investigaciones sobre la Universidad y la educación, UNAM.

Aguirre Salvador, Rodolfo (2018). Cofradías y asociaciones de fieles en la mira de la Iglesia y de la Corona: arzobispado de México, 1680-1750. México: UNAM, Instituto de Investigaciones sobre la Universidad y la Educación.

Aguirre Salvador, Rodolfo (2020). Parroquias (DCH) (Parishes (DCH)). Max Planck Institute for European Legal History Research Paper Series No. 2020-10. DOI: https://dx.doi.org/10.2139/ssrn.3609780

Álvarez Icaza, María Teresa $(\uparrow \cdot 11)$. La reorganización del territorio parroquial de la arquidiócesis de México durante la prelacía de Manuel Rubio y Salinas (- I V 9 १ 1Vro). Hispania Sacra, n. 28, pp. 501-518. DOI: https://doi.org/10.3989/hs.2011. v63.i128.281

Ansón, María del Carmen (1999). Valor documental de las visitas pastorales para estudios de la Edad Moderna. El ejemplo de los pueblos del partido de Cariñena. Memoria Ecclesiae, n. XIV, pp. 325-346.

Arnal, María Rosa (1990). Estudio de Caspe en el siglo XVIII a través de las visitas pastorales e informes parroquiales". Aragonia Sacra, n. 5, pp. 13-32.

Calderón, Germán (1999). La Villa de Almonte según una visita pastoral de 1697. En Cortés, Antonio Luis (coord.). Estudios sobre Iglesia y sociedad en Andalucía en la Edad moderna. Granada: Universidad de Granada, pp. 289-302. 
Calderón, Germán (2000). Nuevas aportaciones sobre la Iglesia en la villa de Manzanilla durante el siglo XVII y la devoción a Nuestra Señora del Valle y Nuestra Señora de la Victoria. Hispania Sacra, n. 52, pp. 163-176.

Cárcel Ortí, María Milagros y Trench Odena, José (1982). Una visita pastoral del pontificado de San Juan de Rivera en Valencia (1570). Separata de la revista Etudis. Revista de Historia Moderna, $\mathrm{n}^{\circ} 8$.

El sacrosanto y ecuménico concilio de Trento (1847), traducido al idioma castellano por D. Ignacio López de Ayala. Con el texto latino corregido según la edición auténtica de Roma publicada en 1564. Nueva edición aumentada con el sumario de la historia del concilio de Trento, escrito por D. Mariamo Latre. Barcelona: Imprenta de D. Ramón Martin Indar.

Garza Martínez, Valentina y Pérez Zevallos Juan Manuel (2007). Las visitas pastorales de Mazapil 1572-1856. Zacatecas: Centro de Investigaciones y Estudios Superiores en Antropología Social Municipio de Mazapil.

López Ferman, Lilia Isabel (2008). Para construir la historia local: los archivos parroquiales. En Bieñko de Peralta, Doris y Bravo Rubio, Berenise (coords.). De brechas, sendas y atajos. Contexto y crítica de las fuentes eclesiásticas de los siglos XVI al XVIII. México: Instituto Nacional de Antropología e Historia/Escuela Nacional de Antropología e Historia, pp. 185-196.

López Tovilla, Virginia Margarita - Viqueira Albán, Juan Pedro (2019). Breve historia del AHDSC, México: Centro de Estudios Históricos, El Colegio de México, Disponible en: https://catalogo-ahdsc.colmex.mx/index.php/base-de-datos/historia-del-ahdsc

Martínez Domínguez, Héctor (1977). Las cofradías en la Nueva España. En Primer Anuario del Centro de Estudios Históricos. Xalapa: Universidad Veracruzana, pp. 45-71.

Mazzone, U, Turchini A. (ed.), (1990). Le visite pastorali. Analisi di una fonte. Bologna: Il Mulino.

Miguel García, Isidoro (1999). El obispo y la práctica de la Visita pastoral en el marco de la teología reformista. Memoria Eclessiae, n. XIV, pp. 347-404.

Monjas, Lluis (1998). La demografía del Baix Llobregat a la Baixa Edat Mitjana a través del concepte de parroquia de les visites pastorals". Materials del Baix Llobregat, n. 4 , pp. 83-85.

Mota y Escobar, Alonso de la (1987). Memoriales del Obispo de Tlaxcala. Un recorrido por el centro de México a principios del siglo XVII. Introducción y notas de González Jácome, Alba. México: SEP.

Palafox y Mendoza, Juan (1997). Relación de la Visita eclesiástica de parte del obispado de Puebla de los Ángeles (1643-1646). Transcripción, introducción y notas de Bernardo García Martínez. Puebla: Secretaría de cultura, Gobierno Estado de Puebla.

Pérez Zevallos Juan Manuel (2011). Las "visitas" como fuente de estudio del tributo y población de la Huasteca (siglo XVI). Itinerarios: revista de estudios lingüisticos, literarios, históricos y antropológicos, n. 12, pp. 41-64. 
La visita pastoral como fuente privilegiada... - A. de Zaballa Beascoechea

Pueyo Colomina, Pilar (1993). Las visitas pastorales: metodología para su explotación científica. En Ubieto Arteta, Agustín (coord.). Metodología de la investigación cientifica sobre fuentes aragonesas, Zaragoza: Universidad de Zaragoza, Instituto de Ciencias de la Educación, pp. 215-270.

Ramos, Gabriela (2019). Los sujetos en la visita pastoral: una mirada a la micropolítica colonial andina. Anuario de Historia de la Iglesia, n. 28, pp. 133-146. DOI: https:// doi.org/10.15581/007.28.133-146

Salinas, María Laura y Pozzaglio, Fernando (2018). La visita Pastoral del obispo Benito Lué a Corrientes, Río de la Plata, a principios del siglo XIX. Res gesta, n. 54, pp. 1-19.

Santiago y León Garabito, Juan de (2009-2010). El Libro de Visita Pastoral del Obispo Garabito O semblanza de la Nueva Galicia en 1678 y 1679. Paleografía de Verónica Cortés Alba. Boletín eclesiástico de la Archidiócesis de Guadalajar[en línea], I-XII-2009 y I-III 2010. Disponible en: https://arquidiocesisgdl.org/ boletin/2009-1-7.php

Segado Gómez, Luis (2016). La parroquia de Villafranca de Córdoba. Una aportación a su historia a través de la visita pastoral de 1590. Preceptos de los visitadores a finales del siglo XVI. En Crónica de Córdoba y sus Pueblos, n. XXII, pp. 571-600.

Tamarón y Romeral, Pedro (1997). Libro registro de la segunda visita de Pedro Tamarón y Romeral, obispo de Durango. Clara Bargellini y Chantal Cramaussel (transcripción, introducción y notas). México: Siglo XXI, Fundación Ignacio Borquez Zazueta.

Tanck de Estrada, Dorothy (2004). Los bienes y la organización de las cofradías en los pueblos de indios del México colonial. Debate entre el Estado y la Iglesia. En María del Pilar Martínez López-Cano, Elisa Speckman Guerra y Gisela von Wobeser (coordinación e introducción). La Iglesia y sus bienes. De la amortización a la nacionalización. México: Universidad Nacional Autónoma de México, Instituto de Investigaciones Históricas, pp. 33-58.

Watson Marrón, Gustavo, González Merlo, Gilberto, Bravo Rubio, Berenise, Pérez Iturbe, Marco Antonio (2002). Guía de documentos Novohispanos del Archivo Histórico del Arzobispado de México. México: Arquidiocesis Primada de México.

Zaballa Beascoechea, Ana de (2016). Una ventana al mestizaje: el matrimonio de los indios en el arzobispado de México, 1660-1686. Revista complutense de Historia de América, n. 42, pp. 73-96. DOI: https://doi.org/10.5209/RCHA.53711

Zaballa, Ana de; Lanchas, Ianire (2017). Conflictos de Jurisdicción a fines del XVIII: El caso del obispo Ortigosa 1776-1793. En Cordero, Macarena, Gaune, Rafael, Moreno, Rodrigo (coords.). Cultura legal y espacios de justicia en América, siglos $X V I-X I X$, Santiago de Chile: Centro de Investigación Diego Barros Arana, pp. 93119. 